\title{
It's time to act on racism in the NHS
}

\author{
Victor Adebowale incoming chair, NHS Confederation, Mala Rao professor, Imperial College London
}

Ethnic minority doctors and patients still face too many injustices in the NHS. The BMJ's special issue on racism in medicine (bmj.com/racism-in-medicine) maps some of them and asks how they might be overcome, from the fivefold higher maternal mortality among black women than among white women in the UK (doi:10.1136/bmj.m442; doi:10.1136/bmj. $\mathrm{m} 424)$ to the gap in performance between white and ethnic minority students and doctors (doi:10.1136/bmj.m438) and the increased likelihood of disciplinary procedures against ethnic minority doctors (doi:10.1136/bmj.m338).

In a joint $B M J$ and BMA investigation Zosia Kmietowicz found that medical schools are poor at recording students' complaints of racial harassment (doi:10.1136/bmj.m420). It is sad to read that students are resigned to the likelihood that nothing will be done if they report a racial incident, so they don't bother. Instead, they internalise the humiliation and prepare for a career where discrimination is commonplace, no doubt affecting their self esteem and their ability to perform. Action needed to close the attainment gap is in the gift of the GMC. To move things forward, the BMA has launched a charter for medical schools and guidance for students "to prevent and effectively deal with racial harassment."

A disappointing theme running through this special issue is the lack of progress. How can it be that a problem raised in The $B M J$ more than 25 years ago-that of discrimination in applications for specialty training posts in the NHS_-persists (doi:10.1136/bmj.m479)? Differential attainment has also featured in the research literature for more than 20 years yet is unlikely to disappear any time soon. In her editorial Katherine
Woolf says that progress requires a better learning environment for ethnic minority students, such as improved support and stronger action on discrimination and harassment, but that this will take leadership and vision (doi:10.1136/bmj.m339).

Another disappointment is that The BMJ's call for research on discrimination and health inequalities related to race, posted last May (doi:10.1136/bmj.12226), did not produce any suitable studies. Does this reflect a research environment uninterested in the causes of ethnic health disparities and possible solutions? To deliver healthcare that better meets the needs of ethnic minority patients, "concerted effort is needed to plug data gaps," say Sarah Salway and colleagues (doi:10.1136/bmj.m268). That means high quality evidence from research that involves patients and the public and informs action. If research fails to include people of all racial backgrounds, artificial intelligence systems that are built using that research will worsen health inequalities, writes Poppy Noor (doi:10.1136/bmj.m363).

Harvard professor David Williams has made the study of race and health his life's work. In an interview for this issue (doi:10. 1136/bmj.m341) he says he would like to see a health observatory established in the UK to look at the effects of racial discrimination on patients. Such research is crucial to bring about the scale of organisational change the NHS needs. "It takes commitment and deliberate concerted action to change an organisation's culture and make a difference," Williams says. "The rhetoric must be matched by behaviour and policies that have teeth and the authority to implement change." We couldn't agree more (doi:10.1136/bmj.m530). 